\title{
Jaguar Panthera onca in its southernmost range: use of a corridor between Bolivia and Argentina
}

\author{
Griet An Erica Cuyckens ${ }^{1,2, *}$, Fernando Falke ${ }^{3}$, Lisanne Petracca ${ }^{4}$ \\ ${ }^{1}$ Consejo Nacional de Investigaciones Científicas y Técnicas (CONICET), Av. Rivadavia 1917 (C1033AAJ), Buenos Aires, \\ Argentina \\ ${ }^{2}$ Centro de Estudios Territoriales Ambientales y Sociales (CETAS), Alberdi 47, 4600 San Salvador de Jujuy, Argentina \\ ${ }^{3}$ Red Yaguareté, Los Toldos s/calle, 4531 Salta, Argentina \\ ${ }^{4}$ Panthera, 8 West 40th Street, 18th Floor, New York, NY 10018, USA
}

\begin{abstract}
Corridors can prevent local extinction of particular species by connecting populations and are crucial for the long-term conservation of large animals and species with large homeranges such as jaguars. To assess the functionality of the proposed Tariquía-Baritú corridor between Bolivia and Argentina, we used the jaguar as a focal species. We conducted 254 interviews with local residents in 103 of 117 sampling units $\left(\right.$ each $36 \mathrm{~km}^{2}$ ) from November 2009 to February 2012, regarding the presence of the jaguar Panthera onca and 6 prey species: the whitelipped peccary Tayassu pecari, collared peccary Pecari tajacu, red brocket deer Mazama americana, gray brocket deer Mazama gouazoubira, capybara Hydrochaeris hydrochaeris and agouti Dasyprocta punctata. We applied site occupancy modeling using environmental covariables. Sampling units effective for jaguar and for the future of the corridor were selected based on having a minimum $65 \%$ likelihood that the jaguar and at least 4 of 6 prey species use habitat within that unit. The final corridor was $3168 \mathrm{~km}^{2}$ and encompassed 88 of the sampling units, suggesting that connectivity still exists between Tariquía Reserve and Baritú National Park and, therefore, that this corridor qualifies for long-term conservation. Changes in human land use, direct hunting and the presence of a route bisecting the study area are considered the main threats to the future of the corridor. Corridors are an effective conservation measure but must be accompanied by other conservation solutions.
\end{abstract}

KEY WORDS: Connectivity - Conservation planning - Detection probability · Interviews . Occupancy $\cdot$ Prey

\section{INTRODUCTION}

Intact forests are being increasingly fragmented, leading to the geographic isolation of subpopulations of species and changing population dynamics (Akçakaya et al. 2007). Creation of protected areas counteracts the rapidly accelerating biodiversity crisis, but these are often not extensive enough to maintain large populations. Furthermore, wide-ranging carnivores regularly extend beyond reserve borders (Woodroffe \& Ginsberg 1998).

\footnotetext{
*Corresponding author: grietcuyckens@yahoo.com
}

Corridors maintain or restore landscape connectivity and serve as a buffer against stochastic events, and constitute an alternative to strictly protected areas (Anderson \& Danielson 1997). Natural landscapes are generally more connected than landscapes altered by humans, and corridors are essentially a strategy to retain or enhance some of this natural connectivity (Noss 1987). Assessing the benefits of corridors for biodiversity conservation is difficult because of the large number of potential influences (MacDonald 2003). Corridors restore

() The authors 2014. Open Access under Creative Commons by Attribution Licence. Use, distribution and reproduction are unrestricted. Authors and original publication must be credited. 
ecosystem services such as water quality, stability of hydrological cycles and microclimate regulation, and contribute to biodiversity conservation (Anderson \& Danielson 1997), and, by facilitating migration and genetic contact between meta-populations, they improve the viability of populations (Beier \& Noss 1998).

In this study we assess the functionality of a binational (Bolivian-Argentinean) corridor focusing on the jaguar Panthera onca and its main types of prey. The jaguar is 'Near Threatened' (Caso et al. 2008), and is the largest felid in the Americas and the third largest in the world. The species' distribution stretches from northern Argentina to Mexico (Zeller 2007), with its geographic range suffering a reduction of approximately $45 \%$ over the last century (Sanderson et al. 2002, Zeller 2007), especially in its southernmost limit (Di Bitetti et al. in press). Jaguars can act as umbrella species, the protection of which indirectly causes the protection of other species, because of its large area requirements (LeaderWilliams \& Dublin 2000). As top predators they play an important role in maintaining healthy ecosystems (Miller \& Rabinowitz 2002). So we assume that if a corridor is useful to jaguars, it will also be useful to several other species and enhance habitat continuity.

The corridor we focus on comprises $4212 \mathrm{~km}^{2}$ at the Bolivia-Argentina border and connects 2 major protected areas with known jaguar presence: Tariquía Flora and the Fauna National Reserve (NR; 246870 ha, Bolivia) and the Baritú National Park (NP; 72439 ha, Argentina). This corridor may be crucial for jaguar populations in both countries as they could otherwise be isolated from distant jaguar populations (Di Bitetti et al. in press, Maffei et al. in press). Empirical data must be collected in order to understand whether this corridor fulfills the requirements for jaguars to move between protected areas and use habitat between them.

Corridors are critical for the long-term conservation of this wide-ranging species, and a critical first step was identifying range-wide least-cost connectivity between known jaguar populations (Rabinowitz \& Zeller 2010). However, this large-scale assessment should be complemented with local information relevant to conservation actions in specific regions or habitats (Salom-Pérez et al. 2010, Zeller et al. 2011, Petracca et al. 2014). The analysis of Sanderson et al. (2002) omitted the Tariquía-Baritú corridor. Based on bi-national efforts this corridor has been proposed and indicates jaguar protection as one of its main goals, but it is yet poorly implemented and no jaguar studies exist (Prometa et al. 2005).
Where carnivores coexist with rural human populations, poaching can deplete their prey base and cause the decline or extinction of local carnivore populations (Robinson \& Bennett 2000) such as the jaguar (Leite \& Galvão 2002). With $>80$ prey species (Seymour 1989), jaguars are characterized as opportunistic predators that feed preferably on medium to large, primarily mammalian prey species, adapting their diet to local conditions (de Oliveira 2002, González \& Miller 2002). It is therefore important to include knowledge about local prey species when investigating corridor functionality. In this study we include 6 main prey species known to be important to jaguars (Perovic 2002): the white-lipped peccary Tayassu pecari, collared peccary Pecari tajacu, red brocket deer Mazama americana, gray brocket deer Mazama gouazoubira, capybara Hydrochaeris hydrochaeris and agouti Dasyprocta punctata.

In a matrix of natural and human-modified landscape, classic inventories such as camera trapping or footprint traps can be inefficient (Zeller et al. 2011). However, local people can be good sources of information about the presence or absence of wildlife (Rabinowitz 1997, White et al. 2005). Therefore, a method based on interviews combined with occupancy modeling was proposed and has been used to assess jaguar corridors (Zeller et al. 2011, Petracca et al. 2013). Site occupancy modeling also provides a flexible framework that enables occupancy to be modeled as a function of covariate information (MacKenzie et al. 2009). The use of covariates, such as land cover type, elevation and human presence, can provide valuable information about the factors influencing habitat use by jaguars and prey species in a human-modified landscape.

Our goal was to assess the functionality of the Tariquía-Baritú corridor by assessing whether it is used by one of the target species and its prey.

\section{MATERIALS AND METHODS}

\section{Study area}

The area falls within the Yungas ecoregion, which represents the southern limit of distribution of an extensive forest system known as Yungas Andean forests (Brown \& Kappelle 2001). The subtropical Yungas range from southern Bolivia to northwestern Argentina (19 to $29^{\circ} \mathrm{S}$ ). Yungas is one of only 3 ecoregions in Argentina where jaguars subsist, and, because of its extension and its relatively good pro- 


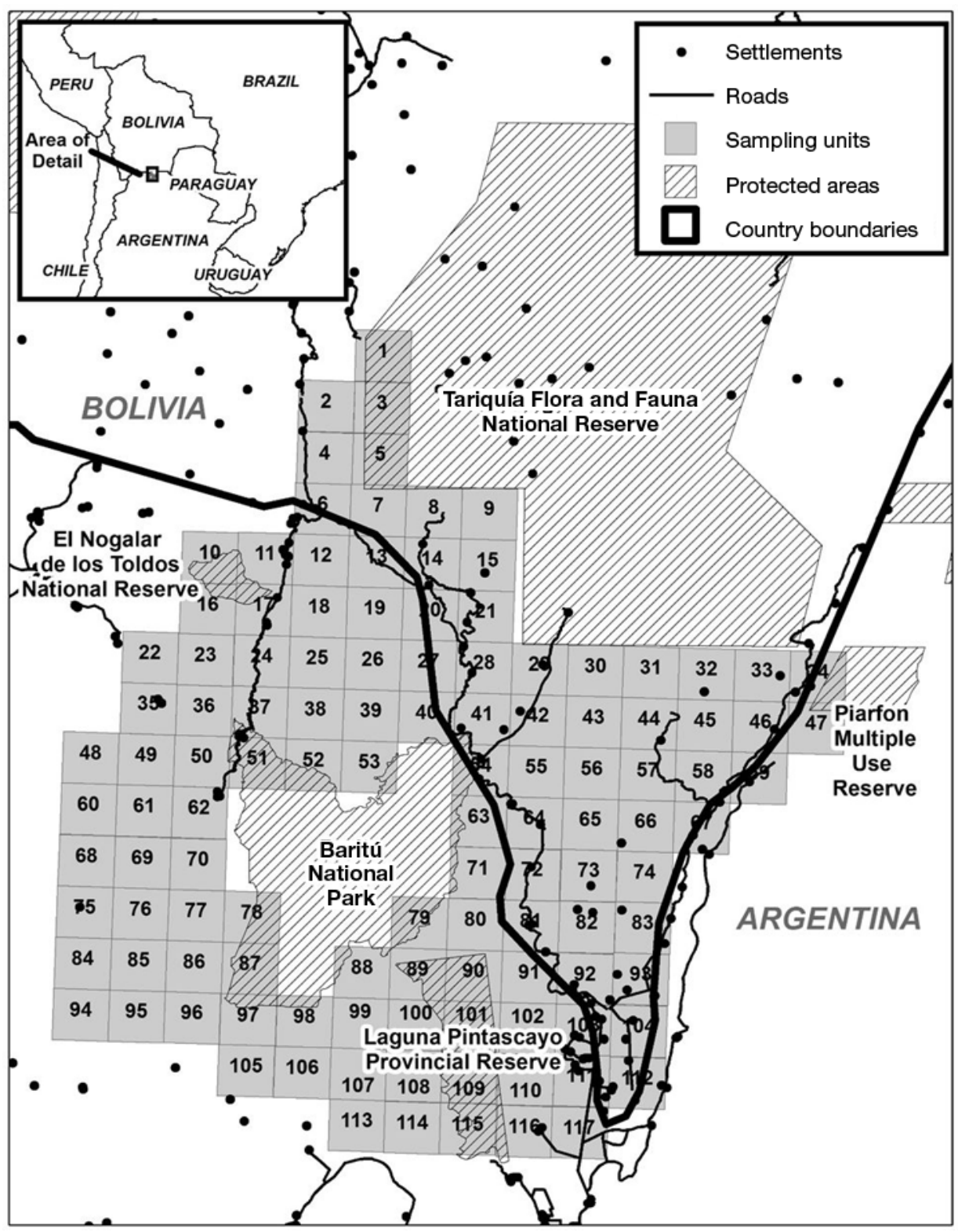

Fig. 1. Tariquía-Baritú corridor study area at the Bolivia-Argentina border, showing the 117 sampling units

tection status, it is crucial for long-term jaguar conservation in the country (Di Bitetti et al. in press). The study area (Fig. 1) exhibits a sharp SE-NW elevation gradient from 286 to $4797 \mathrm{~m}$ above sea level. Following a land cover classification of 2 Landsat images from September 16, 2011, the primary land cover types are forest $(81.64 \%)$, shrubland found on highelevation slopes $(7.04 \%)$ and agriculture $(4.94 \%)$. Important is the presence of a paved route bisecting the study area, parallel to the Bermejo River (a section of which forms the border between Argentina and Bolivia within our study area) and the international border.

\section{Sampling units and interviews}

Changes in humal land use in the corridor mean there is a need to identify which sampling units are providing effective connection. Therefore, we assessed the effectiveness of the Tariquía-Baritú corridor for jaguar following the protocol outlined by Zeller et al. (2011). We divided our study area into $6 \times$ $6 \mathrm{~km}\left(36 \mathrm{~km}^{2}\right)$ sampling units, resulting in 117 sampling units where we conducted from 1 to 9 interviews (mean $=3.8$ ) per sampling unit from November 2009 to February 2012. The sampling unit size of $36 \mathrm{~km}^{2}$ is the same as that outlined by Zeller et al. 
(2011), as it is the minimum estimated home range size of the jaguars Panthera onca in the region. However, as interviews were collected over a period of $2.5 \mathrm{yr}$, we cannot assume a closed population and therefore consider our study more an analysis of habitat use than occupancy. Zeller et al. (2011) reached the same conclusion regarding the interpretation of their findings. We selected independent interviewees, i.e. no relatives or owners of the same cattle. Interviewees were mostly ranchers, who are particularly knowledgeable about wildlife. They were asked whether or not they had seen a jaguar or signs thereof (i.e. tracks) within the last year. To ascertain the knowledge and credibility of the interviewees, we asked them to provide a detailed description of the jaguar and puma and their tracks. This process was repeated for each of the 6 prey species, and, for prey species only, interviewees were asked how frequently these sightings occurred. The following information was also collected from the interviewees: how long they lived in their sampling unit of residence, whether they only traveled to a sampling unit in certain months (i.e. wet or dry season), how many days they spent in a sampling unit per month, and their reason for visitation to a sampling unit (i.e. hunting, farming, ranching).

\section{Covariates and data analysis}

We used PRESENCE V3.1 software (Hines 2010) to analyze data through site-occupancy models, which account for imperfect detection and can be used to estimate the proportion of sites where a species occurs from detection/non-detection data survey data (MacKenzie et al. 2002). Each interview was counted as an independent survey for a sampling unit, and all interviews made up the encounter record for that unit. We created a list of biologically relevant candidate variables based on a priori hypotheses as to how each would affect species habitat use or detection (Table 1). We tested each covariate univariately and retained only those that were statistically significant $(\mathrm{p} \leq 0.05)$, non-confounded and uncorrelated $(|r|<0.5)$ (Hosmer \& Lemeshow 2000). This list of retained variables was considered our final candidate variable set. We then combined these candidate variables in a number of competing models, using Akaike's information criterion with the small-sample correction (AICc) to select the model that best explained variation in species detection and habitat use $(\triangle \mathrm{AICC}<2.0)$ (Burnham \& Anderson 2002). We modeled detection covariates first, and then held our top detection covariates constant while modeling habitat use. All mapping was performed in ESRI ArcMap V10 software.

Land use-land cover data were derived from 2 Landsat (30 m resolution) images from September 16, 2011. Elevation data were collected at $90 \mathrm{~m}$ resolution and obtained from the SRTM V4 database (Jarvis et al. 2008). Protected area data for Argentina were derived from the World Database on Protected Areas (IUCN \& UNEP 2012). Layers of rivers, roads and settlements of the Tariquía-Baritú area were developed by field teams as part of the corridor initiative (Prometa et al. 2005).

\section{Model selection and model averaging}

A single-season model was used to analyze data for all species (MacKenzie et al. 2002). Models were

Table 1. Covariates chosen for site occupancy modeling

\begin{tabular}{|c|c|c|c|}
\hline \multicolumn{2}{|c|}{ Site covariates } & \multirow{2}{*}{\multicolumn{2}{|c|}{$\begin{array}{r}\text { Sampling covariates } \\
\text { Anthropogenic }\end{array}$}} \\
\hline Habitat & Anthropogenic & & \\
\hline 1. Forest $(\%)^{\mathrm{a}}$ & 1. Distance to road $(\mathrm{m})^{\mathrm{b}}$ & 1. Forest $(\%)^{\mathrm{a}}$ & 1. Effort \\
\hline 2. Shrubland $(\%)^{a}$ & 2. Distance to village $(\mathrm{m})^{\mathrm{b}}$ & 2. Shrubland $(\%)^{\mathrm{a}}$ & 2. Residence \\
\hline 3. Bare ground $(\%)^{a}$ & 3. Distance to protected area $(\mathrm{m})^{\mathrm{b}}$ & 3. Bare ground $(\%)^{\mathrm{a}}$ & 3. Distance to road $(\mathrm{m})^{\mathrm{b}}$ \\
\hline 4. Agriculture $(\%)^{\mathrm{a}}$ & & 4. Agriculture $(\%)^{\mathrm{a}}$ & 4. Distance to village $(\mathrm{m})^{\mathrm{b}}$ \\
\hline 5. Water $(\%)^{\mathrm{a}}$ & & 5. Water $(\%)^{\mathrm{a}}$ & 5. Distance to protected area $(\mathrm{m})^{\mathrm{b}}$ \\
\hline $\begin{array}{l}\text { 6. Total vegetation (forest } \\
\text { and shrubland) }(\%)^{\mathrm{a}}\end{array}$ & & $\begin{array}{l}\text { 6. Total vegetation } \\
\text { (forest and shrubland }\end{array}$ & $(\%)^{\mathrm{a}}$ \\
\hline 7. Distance to river $(\mathrm{m})^{\mathrm{b}}$ & & 7. Distance to river $(\mathrm{m})^{\mathrm{b}}$ & \\
\hline 8. Mean elevation $(\mathrm{m})^{\mathrm{a}}$ & & 8. Mean elevation $(\mathrm{m})^{\mathrm{a}}$ & \\
\hline 9. Max. elevation $(\mathrm{m})^{\mathrm{a}}$ & & 9. Max. elevation $(\mathrm{m})^{\mathrm{a}}$ & \\
\hline${ }^{\mathrm{a}}$ As proportion of each sa & ling unit & & \\
\hline
\end{tabular}


ranked using AICc (Burnham \& Anderson 2002). We used $\triangle \mathrm{AIC}$, a measure of each model relative to the best model, to compare models with significant covariates. $\triangle \mathrm{AIC}$ was calculated using the following equation:

$$
\Delta \mathrm{AIC}=\Delta_{i}=\mathrm{AIC}_{i}-\min \mathrm{AIC}
$$

where $\mathrm{AIC}_{i}$ is the AIC value for model $i$ and minAIC is the AIC value for the 'best' (most parsimonious) model. According to Burnham \& Anderson (2002), a $\Delta_{i}<2$ suggests substantial evidence for the model, while $\Delta_{i}$ values of 3 and higher indicate increasingly less support. A $\Delta_{i}>10$ indicates that the model is very unlikely. With these general rules of thumb, we kept only those models with $\Delta_{i}<2.0$. In the event of multiple models with $\Delta_{i}<2.0$, model averaging was used to estimate probabilities of habitat use and detection for that species (Burnham \& Anderson 2002).

\section{Predictive maps and corridor identification}

To identify areas that are effectively useable within the corridor, we applied (1) the likelihood of jaguar habitat use in a sampling unit ( $\Psi$-cond $\left.\mathrm{j}_{\text {jaguar }}\right)$ and (2) the likelihood of at least 4 of 6 prey species (whitelipped and collared peccaries, red and gray brocket deer, capybara, agouti) using habitat in a sampling unit $\left(\Psi\right.$-cond $\left.\mathrm{prey}_{1}\right) . \Psi$-cond prey $_{\text {is }}$ also referred to as the prey probability estimate. We calculated the prey probability estimate using a conditional statement: $\Psi$-cond prey $=$ likelihood of at least 4 prey species $=$ $\Psi$-cond all_species $+\Psi$-cond $6_{6 \text { _species }}+\Psi$-cond 5_species $_{\text {- }}+$ $\Psi$-cond 4_species. $_{\text {. }}$.

We multiplied $\Psi$-cond $d_{\text {jaguar }}$ and $\Psi$-cond $d_{\text {prey }}$ to get

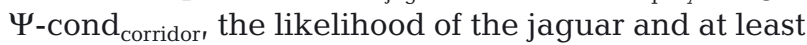
4 of 6 prey species using habitat within each sampling unit. Using the classification method of Jenk's natural breaks, which finds breakpoints in a dataset by maximizing between-group variability while minimizing within-group variability, 0.65 was chosen as the cutoff for habitat use by jaguar and prey. In other words, a sampling unit qualified for the corridor if there was a minimum likelihood of habitat use by the jaguar and at least 4 of 6 prey species of $65 \%$.

\section{RESULTS}

We conducted 254 interviews, with an average of 3.80 interviews per sampling unit. One to nine interviews were collected in 103 of $117(88.03 \%)$ of the sampling units, with no data collected in 14 of the units $(11.97 \%)$, because those areas are geographically isolated and not frequented by human observers. Interviewee age ranged from 17 to $75 \mathrm{yr}$, with a mean age of 46 . Most interviewees were male ( $91.73 \%$ male, $8.27 \%$ female). They spent an average of $97.10 \mathrm{~d}$ of the year $(26.97 \%)$ in the field in each sampling unit (which equates to $8.09 \mathrm{~d} \mathrm{mo}^{-1}$ ) and lived in the area for an average of $35.58 \mathrm{yr}$. The most common activities of interviewees within the sampling units were livestock-rearing, farming and hunting/fishing (Table 2). According to interviewees, major changes to the landscape included increased infrastructure via road paving, a growing human presence along the Bermejo River and an expansion of agricultural areas along the Tarija River, both on the Bolivian side.

Jaguars Panthera onca were widespread (estimated occupancy $=70.87 \%$ ). A single-season, singlestate occupancy model (MacKenzie et al. 2002) was used to estimate habitat parameters for jaguars detected in the sampling units within the last year. There was a higher likelihood of jaguar detection with increasing distance from a settlement (Table 3). The white-lipped peccary was detected in $53.40 \%$ of the sampling units, and habitat use was associated with a lower mean elevation. The collared peccary was detected in $96.12 \%$ of the sampling units, and its detection was associated with less bare ground. Red brocket deer were detected in $97.09 \%$ of the sampling units, and its detection was associated with greater total vegetation. Gray brocket deer were detected in $80.58 \%$ of the sampling units, and its habitat use was associated with lower mean and maximum elevation. Capybaras were detected in $31.07 \%$ of the sampling units. Increased species detection was associated with lower mean elevation (Table 3).

Single-state conditional probability of occupancy ( $\Psi$-cond) was used for the jaguar and all prey species and mapped by sampling unit (Fig. 2). The proba-

Table 2. Main activities within sampling units

\begin{tabular}{|lc|}
\hline Activity & Frequency (\%) \\
\hline $\begin{array}{l}\text { Livestock-rearing (mostly cows, } \\
\quad \text { but also sheep, goats, chickens) }\end{array}$ & 65.99 \\
Farming (planting seed, & 20.3 \\
$\quad$ tending plantations/fincas) & \\
Hunting, fishing & 10.41 \\
Other (patrol, work at gauging & 3.3 \\
$\quad$ station, tourism, work on oil wells) & \\
Total & 100 \\
\hline
\end{tabular}




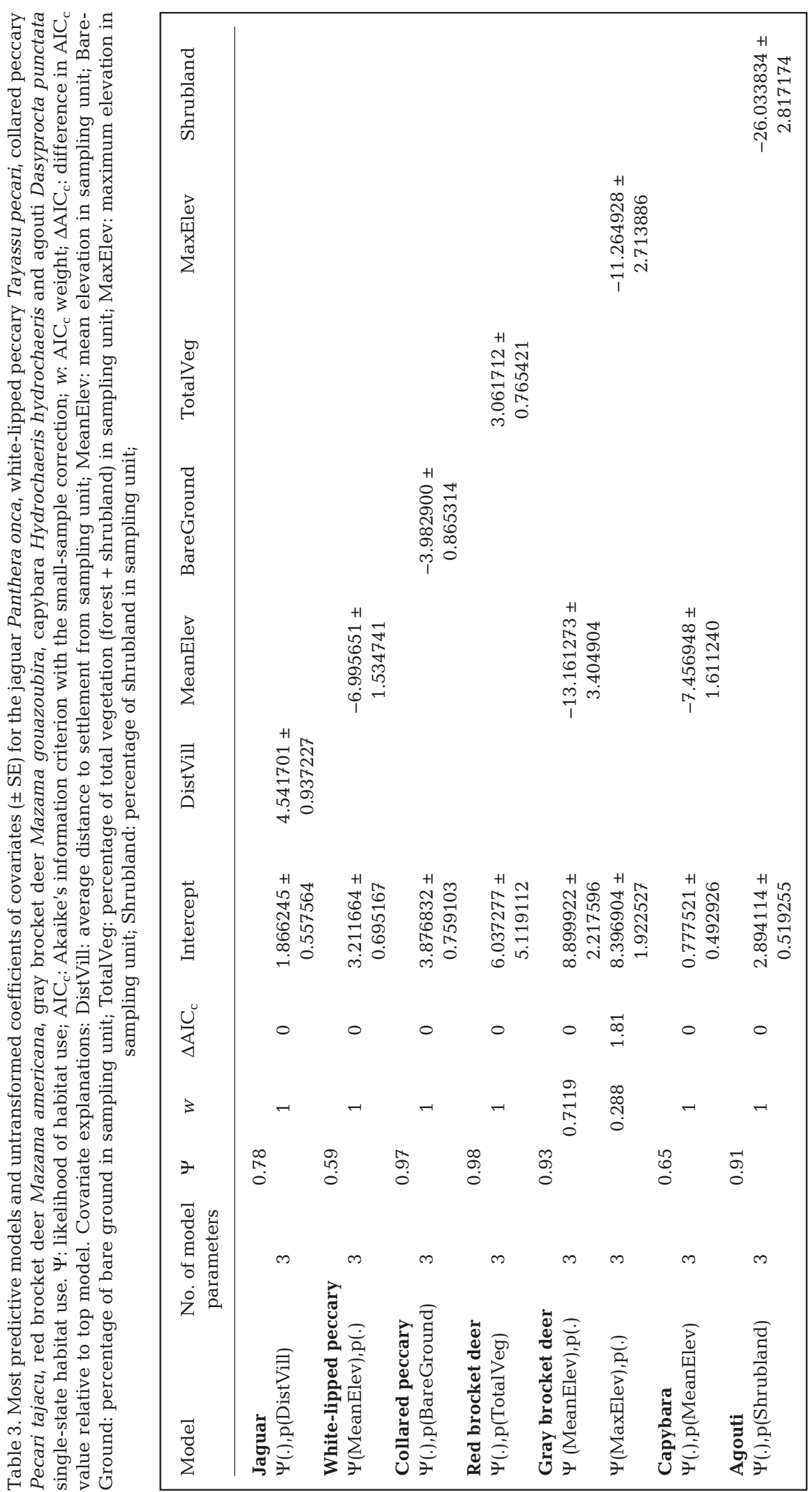




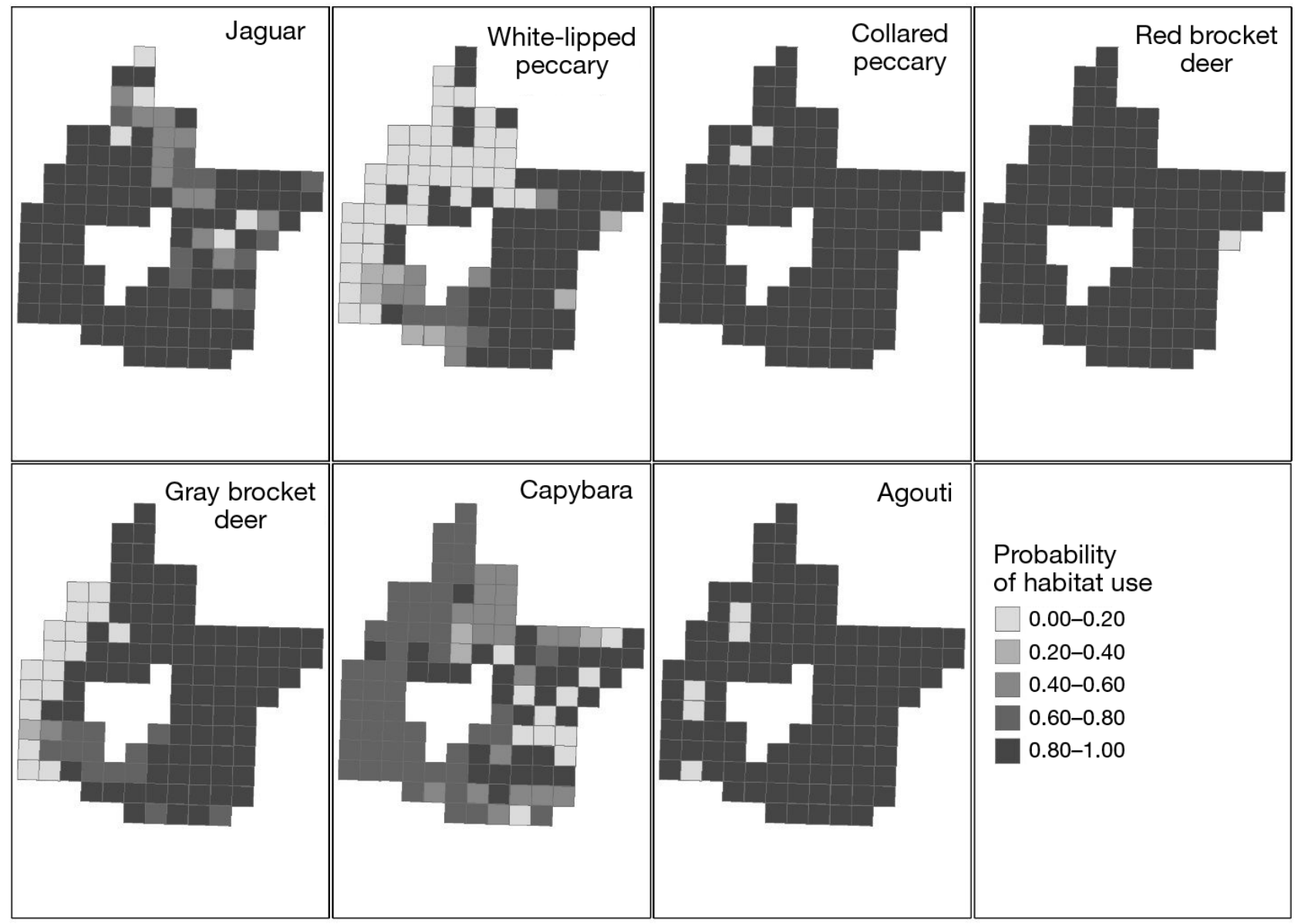

Fig. 2. Estimated probabilities of habitat use by species. See Table 3 legend for taxonomic names

bility estimate used in corridor delineation was

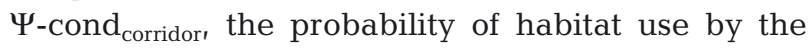
jaguar and at least 4 prey species. This estimate was mapped by sampling unit, with values of at least 0.65 considered suitable for the corridor (Fig. 3). Out of 117 sampling units $(64.10 \%), 75$ had a minimum probability of 0.65 of the jaguar and at least 4 of 6 prey species using habitat within that unit. Seven units were excluded due to concerns of rapidly changing land use (5 units in the southeast) and geographic isolation (2 units in the north). Out of the 117 sampling units $(17.09 \%), 20$ did not qualify for the corridor but were included for connectivity purposes. Thus, 68 sampling units qualified for the final effective corridor of $3168 \mathrm{~km}^{2}$.

\section{DISCUSSION}

Interview results revealed that this area has widespread jaguar (Panthera onca) and prey presence; this was supported by camera trap data inside Baritú NP, where jaguar and all prey species mentioned in this study were recorded (G. A. E. Cuyckens \& P. G. Perovic unpubl. data). However, there are concerns regarding agricultural expansion, the presence of a primary route and secondary routes and direct hunting of jaguars that could threaten the integrity of this corridor. As it stands, there are groups of sampling units that do not qualify for long-term jaguar use and therefore must be prioritized for community outreach if connectivity is to be maintained between Tariquía NR and Baritú NP.

Jaguars were predicted to use habitat in more than three-quarters of the sampling units, with the probability of detection depending on the distance from human settlements (beta DistVill = 4.541701, $\mathrm{SE}=0.937227$; Table 3 ). Though jaguars have been documented to exist across a gradient of human disturbance (Foster et al. 2010), the finding that jaguars are more likely to be detected away from human-impacted areas underscores the jaguar's 

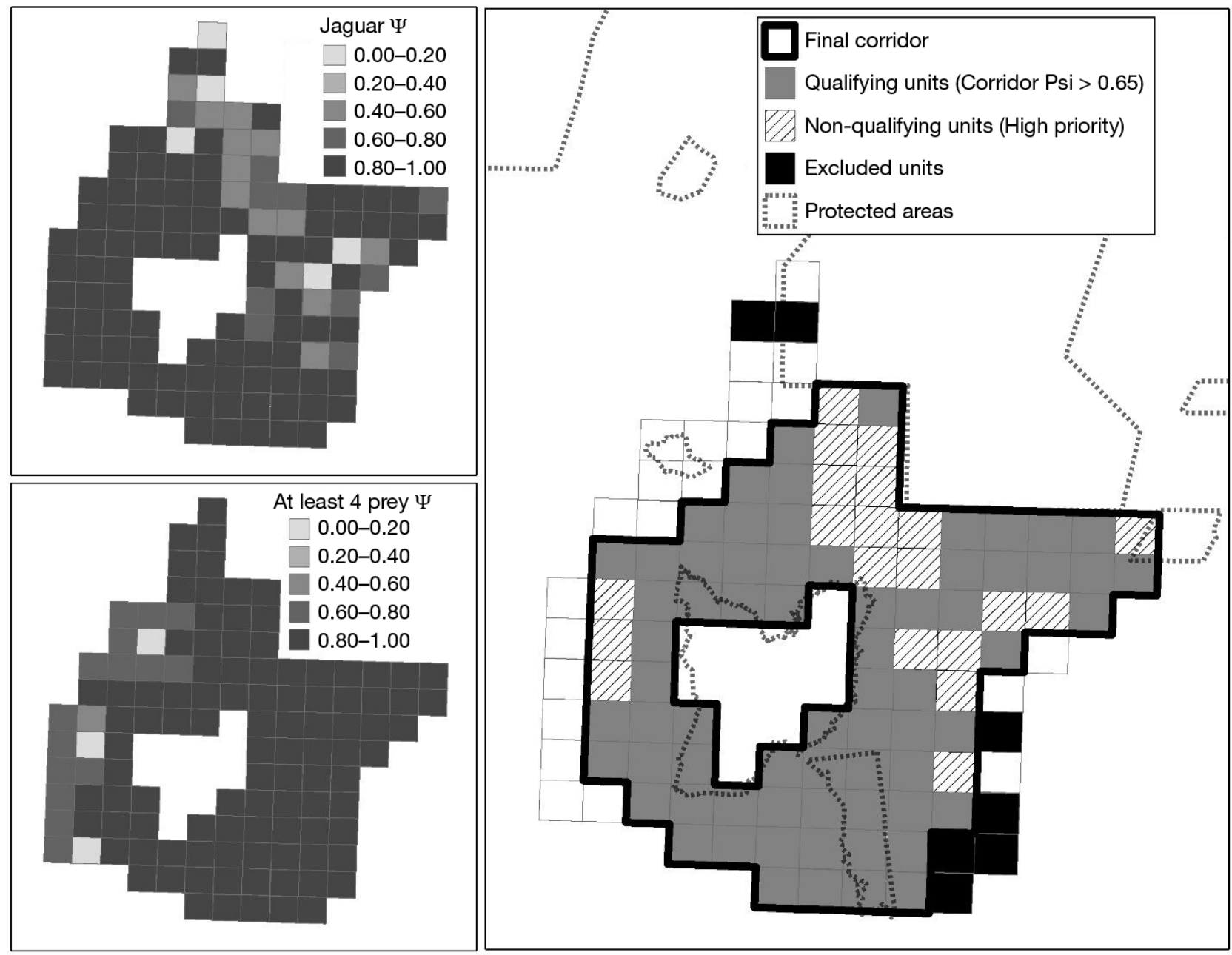

Fig. 3. Probabilities of habitat use by the jaguar Panthera onca and at least 4 prey species by sampling unit. $\Psi$ : likelihood of habitat use

preference for undisturbed habitat (Sunquist \& Sunquist 2002).

The white-lipped peccary had a low estimate of occupancy (0.59), likely related to the fact that this species has been extirpated from parts of its former range. Habitat use increased at lower elevation (beta MeanElev = 6.99, $\mathrm{SE}=1.53$ ). The collared peccary is the most resilient peccary species to habitat change (Altrichter et al. 2006, Tejeda-Cruz et al. 2009) and was therefore much more common than the whitelipped peccary (occupancy $=0.97$ ). Habitat use of the grey brocket deer was associated with lower mean and maximum elevations (beta MeanElev $=-13.16$, $\mathrm{SE}=3.40$ ). Though this species is more of a habitat generalist than the red brocket deer (Rivero et al. 2005), in the study area, it is more common at lower elevations as mentioned before (Richard et al. 1995) and by interviewees. The capybara was the second least common prey species in the study area (occupancy $=0.65$ ), as it has probably been intensively hunted in the past for its fur and is associated with water courses (which provide access for hunters).

In the 7 excluded units, it is likely that prey species continue to be found, but they do not have long-term potential for inclusion in a jaguar corridor. The 20 added sampling units for connectivity purposes were designated 'High Priority' areas because they failed to qualify for the corridor and yet must be included to establish a connection between Tariquía NR and Baritú NP.

This corridor could be crucial for jaguar populations in Argentina and Bolivia, as they may be isolated from other jaguar populations in the rest of those countries and could serve as 'demographic rescue' pools for each other, i.e. genetic exchange between both populations could compensate for a 
poor genetic pool in either one of them individually. The Bolivian population is at the southernmost limit of its distribution and probably has no contact with populations further northward (Maffei et al. in press). The Argentinean population is in the extreme north of the Yungas ecoregion and still has contact with more southern populations. However, the entire Argentinean Yungas population is isolated from the others in this country (Chaco and Atlantic forest populations) and is relatively small (approximately 160 individuals; Di Bitetti et al. in press). To guarantee survival of jaguar in the Argentinean-Bolivian Yungas, connections between different protected areas along the Yungas are crucial, including between Tariquía and Baritú and other smaller (provincial and private) protected areas, as this area has the largest continuous forest in the Yungas (Brown \& Kappelle 2001).

Although routes can act as barriers and cut natural connectivity (Kaczensky et al. 2003, Cáceres 2011) and jaguars avoid routes (Colchero et al. 2011), the route in our study area is fortunately still crossed by jaguars. Interviewees mentioned evidence in 4 places: Balapuca, Quebrada Huacalque-Angosto de Alarachi, Angosto de Arrazayal and Quebrada de Padarón (Sampling Units 54, 13, 81 and 72; Fig. 1). Jaguars cross basically in summer (wet season), making a seasonally based differential use of the corridor, so we can estimate that individuals use a broader area during summer.

However, for the future of the corridor, this international route bisecting the study area is still a major concern as animals can be killed trying to cross it and routes increase exposure to hunting by humans of jaguars and other species such as deer, capybaras, agoutis, peccaries, tapirs, etc. for meat. Additionally, routes provoke an increase in transformation of land to agriculture use along the roadsides, putting connectivity at risk. In the study area, we recorded road killings of felines (ocelots Leopardus pardalis) and other carnivores, e.g. foxes Cerdocyon thous, indicating its risk. The placement of signs along the route to raise awareness of the importance of the area to jaguars, as well as the implementation of speed reduction measures and controls and traffic calming devices could encourage vehicle drivers to reduce their speed. Land use planning may avoid agriculture concentrations.

Another concern is mortality of jaguars as a result of reprisal actions; during our fieldwork we recorded 6 jaguars killed by cattle owners using traps or arms. As ranching is the most common activity within the corridor, proper conflict mitigation measures must be employed if humans and jaguars are to coexist in the area, complemented with awareness raising and controls.

As animals are not confined by political borders, the unit for conservation planning should be the entire biological unit, involving all administrative units and based on bi-national cooperation. Based on interviews, jaguars were previously much wider spread, and have been retracting gradually into the 2 protected areas. This could foretell future isolation of other top carnivores as well, for example, cougars Puma concolor, smaller carnivores such as ocelot and fox and other species with large home ranges such as white-lipped peccary and tapir Tapirus terrestris. Although individual species vary in their use of corridors (MacDonald 2003), the Baritú-Tariquía corridor may qualify as a potentially important corridor for long-term conservation and avoidance of isolation in the 2 main protected areas.

Corridors are an effective conservation measure but must be accompanied by other conservation solutions (MacDonald 2003). In this case, the most pressing interventions recommended are (1) restoring functional connection of high-priority sampling units $(8,14,15,20,21,27,28,29,41$ and 42) between northeastern Baritú NP and Tariquía NR (i.e. via creation of fauna road crossings along the highway); (2) working with private landowners to promote land use compatible with wildlife conservation alongside agriculture; (3) land use plans and design could avoid a concentration of agriculture along the main route and reconcile conservation with other land uses; (4) continuous monitoring of corridor use based on bi-national cooperation; and (5) conflict management and communitybased conservation solutions. This corridor has the potential to reconcile conservation with agricultural cultivation and it can be used as a model to develop similar schemes for geographic priority setting, especially for single-species-based conservation planning.

Acknowledgements. We are grateful to Panthera for financing our fieldwork and to Panthera employees Kathy Zeller and Roberto Salom for their assistance with our methodology. G.A.E.C. received financial support from CONICET. We thank Red Yaguareté for logistic support. We thank Pablo Perovic, Marcelo Montero, Claudia Öller (Prometa), Marcela Zamora (Nativa) and Andrew Noss for support during the study. We also thank Nelson Flores (Agrosic) for GIS layers, and Martin Fisher for revision of previous versions of this manuscript and advice. We especially thank all our interviewees for their support and for sharing their knowledge. 


\section{LITERATURE CITED}

Akçakaya HR, Mills G, Doncaster CP (2007) The role of metapopulations in conservation. In: Macdonald DW, Service K (eds) Key topics in conservation biology. Blackwell Publishing, Oxford, p 64-84

Altrichter M, Boaglio G, Perovic P (2006) The decline of jaguars Panthera onca in the Argentine Chaco. Oryx 40: 302-309

> Anderson GS, Danielson BJ (1997) The effects of landscape composition and physiognomy on metapopulation size: the role of corridors. Landscape Ecol 12:261-271

> Beier P, Noss RF (1998) Do habitat corridors provide connectivity? Conserv Biol 12:1241-1252

Brown AD, Kappelle M (2001) Situación ambiental de los Bosques Andinos Yungueños. In: Kappelle M, Brown AD (eds) Bosques nublados de Latinoamerica. INBio, Santo Domingo de Heredia, p 25-40

Burnham KP, Anderson DR (2002) Model selection and multimodel interference: a practical informationtheoretic approach, 2nd edn. Springer, New York, NY

> Cáceres NC (2011) Biological characteristics influence mammal road kill in an Atlantic Forest-Cerrado interface in south-western Brasil. Ital J Zool 78:379-389

Caso A, Lopez-Gonzalez C, Payan E, Eizirik E, Oliveira T de, Leite-Pitman R, Kelly M, Valderrama C (2008) Panthera onca. IUCN Red List of Threatened Species, Version 20121. International Union for Conservation of Nature, Cambridge

Colchero F, Conde DA, Manterola C, Chávez C, Rivera A, Ceballos G (2011) Jaguars on the move: modeling movement to mitigate fragmentation from road expansion in the Mayan Forest. Anim Conserv 14:158-166

de Oliveira TG (2002) Ecología comparativa de la alimentación del jaguar y del puma en el neotrópico. In: Medellin RA, Equihua C, Chetkiewicz CL, Crawshaw Jr PG and others (eds) El jaguar en el nuevo milenio. Fondo de Cultura Económica, Universidad Nacional Autonoma de Mexico, and the Wildlife Conservation Society, Mexico DF, p 265-288

Di Bitetti M, De Angelo C, Quiroga V, Altrichter M, Paviolo A, Cuyckens GAE, Perovic PG (in press) Estado de conservación del jaguar en la Argentina. In: Medellin RA, Chávez C, de la Torre A, Zarza H, Ceballos G (eds) El jaguar en el siglo XXI: la perspectiva continental. Fondo de Cultura Económica, Mexico DF

Foster RJ, Harmsen BJ, Doncaster CP (2010) Habitat use by sympatric jaguars and pumas across a gradient of human disturbance in Belize: habitat use by jaguars and pumas. Biotropica 42:724-731

González CAL, Miller BJ (2002) Do jaguars (Panthera onca) depend on large prey? West N Am Nat 62:218-222

Hines JE (2010) PRESENCE - Software to estimate patch occupancy and related parameters. US Geological Survey-Patuxent Wildlife Research Center. Available at: http://www.mbr-pwrc.usgs.gov/software/presence.html

Hosmer DW, Lemeshow S (eds) (2000) Applied logistic regression, 2nd edn. Wiley, New York, NY

IUCN \& UNEP (International Union for Conservation of Nature, United Nations Environment Program) (2012) The world database on protected areas (WDPA). UNEPWCMC, Cambridge

Jarvis A, Reuter HI, Nelson A, Guevara E (2008) Hole-filled SRTM for the globe, Version 4. http://srtm.csi.cgiar.org - Kaczensky P, Gossow H, Knauer F, Krze B, Jonozovic M,
Adamic M (2003) The impact of high speed, high volume traffic axes on brown bears in Slovenia. Biol Conserv 111:191-204

Leader-Williams N, Dublin HT (2000) Charismatic megafauna as 'flagship species'. In: Entwistle A, Dunstone N (eds) Priorities for the conservation of mammalian diversity: Has the panda had its day? Cambridge University Press, Cambridge, p 53-81

Leite MRP, Galvão F (2002) El jaguar, el puma y el hombre en tres áreas protegidas del bosque atlántico costero de Paraná, Brasil. In: Medellin R, Equihua C, Chetkiewicz C, Crawshaw $\mathrm{P}$ and others (eds) El jaguar en el nuevo milenio. Fondo de Cultura Económica, Universidad Autónoma de México, Wildlife Conservation Society, Mexico DF, p 237-250

MacDonald MA (2003) The role of corridors in biodiversity conservation in production forest landscapes: a literature review. Tasforests 14:41-52

MacKenzie DI, Nichols JD, Lachman GB, Droege S, Andrew Royle J, Langtimm CA (2002) Estimating site occupancy rates when detection probabilities are less than one. Ecology 83:2248-2255

> MacKenzie DI, Nichols JD, Seamans ME, Gutiérrez RJ (2009) Modeling species occurrence dynamics with multiple states and imperfect detection. Ecology 90: 823-835

Maffei L, Rumiz D, Arispe R, Cuéllar E, Noss A (in press) Estado de conservación del jaguar en Bolivia. In: Medellin R, Chávez C, de la Torre A, Zarza H, Ceballos G (eds) El jaguar en el Siglo XXI: la perspectiva continental. Fondo de la Cultura Económica, México DF

Miller B, Rabinowitz A (2002) Why conserve jaguar? In: Medellin RA, Equihua C, Chetkiewicz CB, Crawshaw Jr PG and others (eds) El jaguar en el nuevo milenio. Fondo de Cultura Económica, Universidad Nacional Autonoma de Mexico, and the Wildlife Conservation Society, Mexico DF, p 210-216

> Noss RF (1987) Corridors in real landscapes: a reply to Simberloff and Cox. Conserv Biol 1:159-164

Perovic PG (2002) Ecología de la comunidad de félidos en las selvas nubladas del Noroeste argentino. Universidad Nacional de Córdoba, Córdoba

> Petracca LS, Ramírez-Bravo OE, Hernández-Santín L (2014) Occupancy estimation of jaguar Panthera onca to assess to value of east-central Mexico as a jaguar corridor. Oryx 48:133-140

Prometa, Sernap, APN-DRNOA ( ) (2005) Corredor Ecológico binacional Tariquía (Bolivia) - Baritú (Argentina). Prometa, Sernap, APN-DRNOA, Tarija

Rabinowitz AR (1997) Wildlife field research and conservation training manual. Wildlife Conservation Society, New York, NY

Rabinowitz A, Zeller KA (2010) A range-wide model of landscape connectivity and conservation for the jaguar, Panthera onca. Biol Conserv 143:939-945

Richard E, Juliá JP, Samaniego J, Aceñolaza P (1995) La corzuela parda. Facultad de Ciencias Naturales e Instituto Miguel Lillo, UNT, Tucumán

Rivero K, Rumiz DI, Taber AB (2005) Differential habitat use by two sympatric brocket deer species (Mazama americana and M. gouazoubira) in a seasonal Chiquitano forest of Bolivia. Mammalia 69:169-183

Robinson JG, Bennett EL (eds) (2000) Hunting for sustainability in tropical forests. Columbia University Press, New York, NY 
Salom-Pérez R, Polisar J, Quigley H, Zeller K (2010) Iniciativa del corredor del jaguar: un corredor biológico y un compromiso a largo plazo para la conservación. Mesoamericana 14:25-34

Sanderson EW, Redford KH, Chetkiewicz CLB, Medellin RA, Rabinowitz AR, Robinson JG (2002) Planning to save a species: the jaguar as a model. Conserv Biol 16:58-72

Seymour KL (1989) Panthera onca. Mamm Species 340:1-9

Sunquist M, Sunquist F (2002) Wild cats of the world. The University of Chicago Press, Chicago, IL

Tejeda-Cruz C, Naranjo EJ, Cuarón AD, Perales H, CruzBurguete JL (2009) Habitat use of wild ungulates in fragmented landscapes of the Lacandon Forest, southern Mexico. Mammalia 73:211-219

Editorial responsibility: Luigi Boitani,

Rome, Italy
White PCL, Jennings NV, Renwick AR, Barker NHL (2005) REVIEW: Questionnaires in ecology: a review of past use and recommendations for best practice. J Appl Ecol 42: 421-430

Woodroffe R, Ginsberg JR (1998) Edge effects and the extinction of populations inside protected areas. Science 280:2126-2128

Zeller K (2007) Jaguars in the new millennium data set update: the state of the jaguar in 2006. Wildlife Conservation Society, New York, NY

Zeller KA, Nijhawan S, Salom-Pérez R, Potosme SH, Hines JE (2011) Integrating occupancy modeling and interview data for corridor identification: a case study for jaguars in Nicaragua. Biol Conserv 144:892-901

Submitted: February 21, 2014; Accepted: August 1, 2014 Proofs received from author(s): October 23, 2014 